\title{
Causes of severe visual impairment and blindness in children attending schools for the visually handicapped in the Czech Republic
}

\author{
I Kocur, P Kuchynka, S Rodný, D Baráková, E C Schwartz
}

\begin{abstract}
Aims-To describe the causes of severe visual impairment and blindness in children in schools for the visually handicapped in the Czech Republic in 1998. Methods-Pupils attending all 10 primary schools for the visually handicapped were examined. A modified WHO/PBL eye examination record for children with blindness and low vision was used.

Results-229 children (146 males and 83 females) aged 6-15 years were included in the study: 47 children had severe visual impairment $(20.5 \%)$ (visual acuity in their better eye less than 6/60), and 159 were blind $(69.5 \%)$ (visual acuity in their better eye less than 3/60). Anatomically, the most affected parts of the eye were the retina (124, 54.2\%), optic nerve $(35,15.3 \%)$, whole globe $(25,10.9 \%)$, lens $(20,8.7 \%)$, and uvea (12, 5.2\%). Aetiologically (timing of insult leading to visual loss), the major cause of visual impairment was retinopathy of prematurity (ROP) $(96,41.9 \%)$, followed by abnormalities of unknown timing of insult $(97,42.4 \%)$, and hereditary disease $(21,9.2 \%)$. In 90 children (40\%), additional disabilities were present: mental disability (36, 16\%),
\end{abstract} 6 April 2001

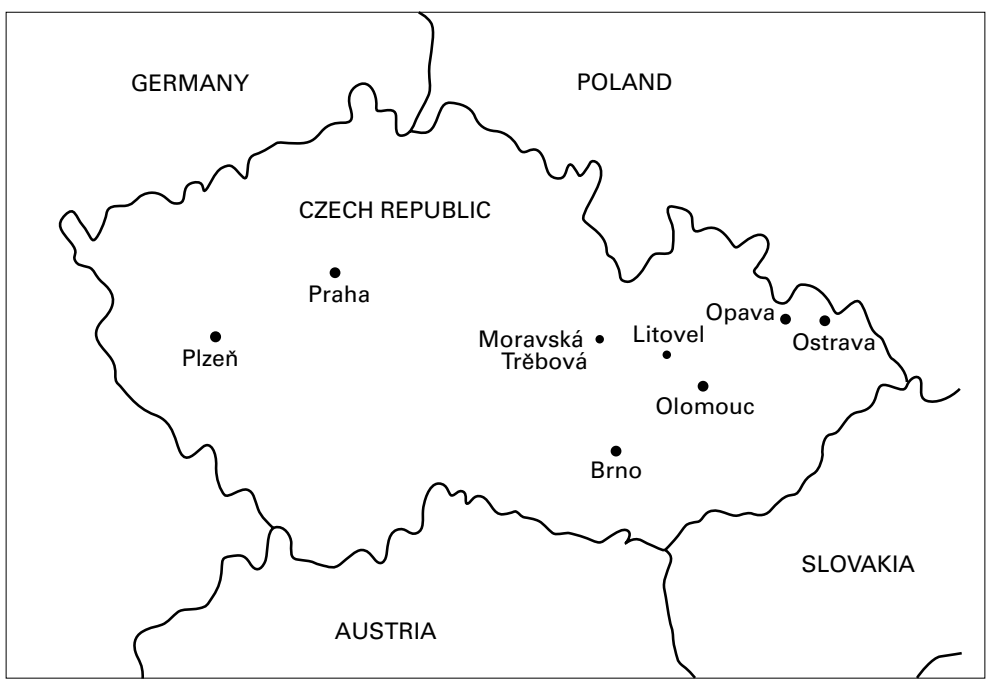

Figure 1 Map of Czech Republic showing main cities. physical handicap (16, 7\%), and/or a combination of both $(19,8 \%)$. It was estimated that 127 children (56\%) suffer from visual impairment caused by potentially preventable and/or treatable conditions (for example, ROP, cataract, glaucoma).

Conclusions-Establishing a study group for comprehensive evaluation of causes of visual handicap in children in the Czech Republic, as well as for detailed analysis of present practice of screening for ROP was recommended.

(Brf Ophthalmol 2001;85:1149-1152)

Information is lacking on magnitude and causes of visual impairment in the eastern European region, which would facilitate the planning of programmes for eye health care. ${ }^{1}$ This study was designed to investigate the causes of severe visual impairment and blindness in children attending schools for the visually handicapped in the Czech Republic. In the Czech Republic, healthcare services are administered centrally and cover the whole country. Eye health care is provided through government hospitals and private practices. The facilities for visually handicapped children are state owned and run by the local authorities. There are state operated regional centres offering their advisory services to families with visually handicapped children. Visually handicapped children are recommended for a particular primary school based on their actual visual acuity and additional disabilities, as well as on their family conditions. Teaching curricula and methods in the primary schools for the visually handicapped are designed for children with severe visual impairment and blindness. The class groups are small and, if necessary, children follow their individual learning programme, which may exceed 1-2 years the regular primary school period. The schools for the visually handicapped also provide optional accommodation for pupils during working days, which is mostly appreciated by families from rural regions. Children with better vision and no limiting additional disabilities are advised to attend regular primary schools.

In 1998 the population of the Czech Republic was 10309137 and the area was 78.9 square kilometres. The number of children aged 6-15 years was $1323587 .^{2}$ There was 
neither a centrally administered list of visually handicapped children in the Czech Republic, nor a record of visually handicapped children attending regular primary schools.

\section{Subjects and methods}

All primary schools for visually handicapped children in the Czech Republic were visited (Prague, Pilsen, Brno, Opava, Ostrava, Moravska Trebova, and Litovel). ${ }^{3}$ In addition, the main school for deaf and visually handicapped children in the Czech Republic was included in the study (Svaty Kopecek). The cities of Prague, Brno, and Pilsen are the main urban areas in the Czech Republic (Fig 1).

Schools keep a personal record for each child, which also includes regular medical reports. All children attending schools for the visually handicapped are seen by an ophthalmologist at least once to twice a year. Reports on an eye examination state current visual acuity, best correction, ophthalmic finding, and recommended treatment. If necessary, according to children's eye conditions (for example, glaucoma, preoperative and postoperative period, etc), they are seen more frequently.

A modified WHO/PBL examination record for children with blindness and low vision was used to describe the child's and family medical history, present health status, visual acuity, additional disabilities, onset of visual loss, the most affected anatomical part of the eye concerning visual impairment, and the aetiological category of the child's disorder based on the timing of insult leading to visual loss. ${ }^{4}$ Personal data, family and medical history information were obtained from personal records of children and by interviewing children and teachers. All children were seen by the first author. Visual acuity was assessed using an illiterate Snellen E chart with the current spectacle correction. Those with visual acuity in the better eye less than $6 / 60$ were recorded as severely visually handicapped (visual acuity in their better eye less than 6/60), or blind (visual acuity in their better eye less than $3 / 60) .{ }^{5}$ All children underwent an eye examination with a torch, portable slit lamp, and indirect and direct ophthalmoscope. Intraocular pressure, visual field, and refraction were not assessed because of limited resources. Additional disabilities were recorded according to observation and the child's medical records. Some children were unable to complete the functional vision test because of additional disabilities or a lack of cooperation. For children absent on the day of the visit, information was gathered on the basis of their school records. Those children were recorded as either "not tested" or "not seen." Children requiring further investigations or treatment were recorded for referral. EPI-INFO statistical software was used to analyse and summarise the data. ${ }^{5}$

\section{Results}

VISUAL FUNCTION

A total of 229 children (146 males and 83 females) aged 6-15 years were included in the study; 47 children had severe visual impairment $(20.5 \%)$ and 159 were blind $(69.5 \%)$.
Table 1 Major site of abnormality leading to visual loss for the child

\begin{tabular}{lrr}
\hline Site of abnormality & \multicolumn{1}{c}{ No } & \multicolumn{1}{c}{$\%$} \\
\hline Whole globe & 25 & 10.9 \\
Cornea & 4 & 1.8 \\
Lens & 20 & 8.7 \\
Uvea & 12 & 5.2 \\
Retina & 124 & 54.2 \\
Optical nerve & 35 & 15.3 \\
Globe appears normal & 9 & 3.9 \\
Total & 229 & 100 \\
\hline
\end{tabular}

Vision tests were not performed on seven children (3\%) for lack of cooperation ("not tested"), and in 16 children (7\%) who were absent on the day of the visit ("not seen"). The data on these children were extracted from their medical records. Among those who were tested, there were 101 children (49\%) with sufficient vision to be able to move around, 75 children $(36 \%)$ were able to recognise faces, and $82(40 \%)$ were able to read standardised $2 \mathrm{~cm}$ large print.

\section{ANATOMICAL SITE AFFECTED}

The posterior segment, retina, and the optic nerve were found to be the most frequently affected sites of the eye (Table 1). Retinal disorders comprise retinopathy of prematurity in 96 children (41.9\%), retinal dystrophies in $27(11.8 \%)$, and retinoblastoma in one child $(0.4 \%)$. Optic nerve atrophy and hypoplasia were present in 35 children $(15.3 \%)$. Conditions affecting the whole globe (for example, anophthalmos, microphthalmos, buphthalmos, or removed globe) were identified in 25 children (10.9\%). Disorders of the lens, mostly aphakia following surgery of congenital cataracts, were found in 20 cases $(8.7 \%)$. These were followed by affections of uvea (for example, aniridia, coloboma, uveitis) in 12 children $(5.2 \%)$. The globe appeared normal in five children with refractive error $(2.2 \%)$ and four children with cortical blindness (1.8). Corneas affected by scarring and dystrophy were found in four children $(1.8 \%)$.

TIMING OF INSULT LEADING TO VISUAL LOSS Aetiological classification reflected timing of insult leading to visual loss (Table 2). The most frequent single condition was retinopathy of prematurity (ROP), the disorder related to the perinatal and neonatal periods. It was found in

Table 2 Aetiology according to timing of insult leading to visual loss

\begin{tabular}{|c|c|c|}
\hline Aetiology & No & $\%$ \\
\hline Hereditary disease & 21 & 9.2 \\
\hline \multicolumn{3}{|l|}{ Intrauterine factors } \\
\hline Toxoplasmosis & 1 & 0.4 \\
\hline \multicolumn{3}{|l|}{ Perinatal/neonatal factor } \\
\hline Cerebral hypoxia & 4 & 1.8 \\
\hline ROP & 96 & 41.9 \\
\hline \multicolumn{3}{|l|}{ Postnatal/infancy factor } \\
\hline Neoplasma & 4 & 1.8 \\
\hline Trauma & 1 & 0.4 \\
\hline Other & 5 & 2.2 \\
\hline \multicolumn{3}{|l|}{ Unknown aetiology } \\
\hline Cataract & 19 & 8.3 \\
\hline Glaucoma & 12 & 5.2 \\
\hline Retinoblastoma & 3 & 1.3 \\
\hline Abnormality since birth & 63 & 27.5 \\
\hline Total & 229 & 100 \\
\hline
\end{tabular}


Table 3 General assessment

\begin{tabular}{lrr}
\hline Disability & No & \multicolumn{2}{c}{$\%$} \\
\hline None & 139 & 60.7 \\
Mental retardation & 36 & 15.7 \\
Physical handicap & 16 & 7.0 \\
Combined mental and physical handicap & 19 & 8.3 \\
Other (epilepsy, hearing loss, etc) & 19 & 8.3 \\
Total & 229 & 100
\end{tabular}

96 children $(41.9 \%)$. The same timing of occurrence was considered in four children with cerebral hypoxia $(1.8 \%)$.

Conditions of unknown timing of insult leading to visual loss followed (97, 42.4\%). They comprised optic nerve atrophy and hypoplasia (30, 13.1\%), cataract $(19,8.3 \%)$, glaucoma $(12,5.2)$, refractive disorders (10, $4.5 \%)$, uveitis $(7,3.1 \%)$, corneal dystrophy $(2$, $0.9 \%)$, retinoblastoma $(3,1.3 \%)$, and disorders of presumed prenatal onsetmicrophthalmos (10, 4.4\%), aniridia (2, $0.9 \%)$, anophthalmos (1, 0.4\%), and coloboma iridis $(1,0.4 \%)$.

Hereditary diseases were present in 21 $(9.2 \%)$ children-retinal dystrophy, Stargardt's disease, achromatopsia, albinismus, and corneal dystrophy.

Conditions related to the postnatal and infancy periods were found in 10 children $(4.5 \%)$ (for example, neoplasma, trauma). The intrauterine acquired condition, toxoplasmosis, was present in one child $(0.4 \%)$.

ADDITIONAL FINDINGS

No evidence of consanguinity was found. Fifteen children showed a positive family history for their condition (four congenital cataracts, four congenital glaucomas, three siblings with ROP, two retinal dystrophies, one microphthalmos, and one albinism). In all cases of ROP, visual impairment developed within the first year of life. Visual loss related to genetic disorders, corneal and retinal dystrophies, neoplasm and disorders of the CNS occurred later in life. The most frequent additional disability was mental disability (36, $15.7 \%)$, followed by physical handicap (16, $7.0 \%)$ and a combination of both $(19,8.3 \%)$ (Table 3). The majority of surgical interventions were for cataract $22(9.6 \%)$, glaucoma 10 $(4.3 \%)$, or a combination of both $(4,1.8 \%)$. Four children with ROP had undergone retinal cryopexies.

Assessment for low vision aids was recommended in seven children. One child with corneal dystrophy was referred for further evaluation for possible surgery. For the majority of children, the prognosis for their vision remains stable. In some children with retinal dystrophies, characterised by a later onset, there is a risk of further progression and deterioration of the remaining vision.

\section{Discussion}

DEMOGRAPHIC DATA

The preponderance of boys found in this study ( $63.8 \%$ boys and $36.2 \%$ girls) is surprising and does not reflect the situation in the general population. In the Czech Republic there were $48.6 \%$ of boys and $51.4 \%$ of girls in the general population from 6 to 15 years of age. ${ }^{2}$ The general awareness of schools for visually handicapped children seems to be appropriate. There is, to our knowledge, no custom or tradition in the Czech Republic, which prefers boys to girls for schooling.

CAUSES OF VISUAL DISABILITY

Retinopathy of prematurity, with 96 cases $(42 \%)$, was the most frequent cause of visual loss according to both anatomical and aetiological classifications. The available data on visual disability due to ROP globally are still patchy. Generally, countries may be categorised into three main groups: countries with minimal or no established neonatal intensive care system, where ROP is a minor problem, countries where neonatal services are increasingly provided but screening and treatment facilities for ROP are unavailable or limited, and countries with highly developed neonatal intensive care services, screening and treatment programmes for ROP. ${ }^{67}$

ROP is a leading cause of visual loss particularly in those countries where advanced technology has led to increasing survival rates for neonates but the infrastructure for ROP control is limited. The proportion of visual disability due to ROP among children in schools for the visually handicapped was $25.9 \%$ in Bulgaria, $38.6 \%$ in Cuba, and $2 \%$ in Romania. ${ }^{8}$ In Slovakia, the occurrence of ROP in one school was $6.2 \%$ and $24 \%$ in another. ${ }^{910} \mathrm{~A}$ study of schools for the blind in Chile showed ROP responsible for $17 \%$ of childhood blindness, ${ }^{11}$ in Ireland for $11.8 \% .^{12}$ Studies carried out in Scandinavia show a decrease within one decade from $10 \%$ to $4 \% .^{13}{ }^{14}$

The second largest group had structural eye abnormalities without any known family history or exposure (63 cases, $28.5 \%$ ). In Scandinavia, optic nerve atrophy of undetermined origin was observed in $1.6 \%$; however, optic atrophy secondary to disorders of the CNS was in $18.8 \%$. Optic nerve hypoplasia was found in $4.9 \%$ and microphthalmos in $1.3 \% .{ }^{13}{ }^{14}$ In Ireland, optic nerve atrophy present at birth was found in $12.2 \%$, optic nerve hypoplasia in $5.2 \%$, and microphthalmos in $2.9 \% .{ }^{12}$ Results from Slovakia are close to the findings of this study. Optic atrophy was present in $14.7 \%$ and microphthalmos in $8 \% .{ }^{90}$ However, since different methodologies were used in the studies mentioned above, the findings are difficult to compare.

The third most common cause of blindness was genetic conditions in 21 children $(9.2 \%)$. Genetic disorders are quite frequently seen among causes of childhood blindness in industrial countries. ${ }^{15}{ }^{16}$ To date the only possible route to prevention is an appropriate genetic family counselling.

This study can at best give an indication that there may be an unusually high proportion of ROP among children with visual disabilities in special schools in the Czech Republic. However, it is not suited to make any statement on possible causes leading to this observation. In the Czech Republic, the available technology in obstetrics and neonatal care frequently 
meets high standards. A high number of cases of ROP found in schools for the visually handicapped requires further attention and assessment of the screening and referral systems in place.

\section{Conclusions and recommendations}

It was estimated that 127 of the children (56\%) suffer from visual impairment caused by potentially preventable or treatable conditions (for example, ROP, cataract, glaucoma).

The main conditions amenable to the prevention of blindness by treatment were through the prevention of retinopathy of prematurity. Other treatments were for children with early onset cataract and early onset glaucoma. Few children that we examined had visual disability that was acquired in the childhood years.

The amount of potentially avoidable blindness due to ROP appears to be high. Further evaluation of factors leading to visual loss in children is highly desirable. It may be helpful to form a study group consisting of ophthalmologists and pediatricians that would concentrate on the following:

- Identifying neonatological departments in the country and establish cooperation with one or two ophthalmologists who would provide screening of children at risk of ROP on a regular basis

- Providing education and practical skill transfer on prevention and treatment of ROP through postgraduate teaching courses

- Conducting a comprehensive national study on prevalence and incidence of visual impairment in children in the Czech Republic.
This work was sponsored by Christoffel-Blindenmission. We gratefully acknowledge the assistance of Dr Clare Gilbert and Dr Allen Foster, and the involvement of all teachers and ophthalmologists from schools for the visually handicapped in the Czech Republic.

1 Thylefors B, Negrel AD, Pararajasegaram R, et al. Available data on blindness. Ophthalmic Epidemiol 1995;2:5-39.

2 Czech Statistical Bureau. Annual Statistical report-Czech statistical bureau 1998. Prague 1999.

3 Campbell LF, Mortimer R. International Council for Education of the Visually Handicapped-International Resource Directory 1992:28-31.

4 Gilbert C, Foster A, Negrel A, et al. Childhood blindness: a new form for recording causes of visual loss in children. Bull World Health Organ 1993;71:485-9.

5 Burton AH, Dean JA, Dean AG. Software for data management and analysis in epidemiology. World Health Forum 1990;11:75-7

6 World Health Organization. Prevention of childhood blindness. Geneva: WHO, 1992

7 Johnson GJ, Minassian DC, Weale R. The epidemiology of eye disease. Philadelphia: Lippincott-Raven Publishers, 1998: 180-207.

8 Gilbert CE, Rahi J, Eckstein M, et al. Retinopathy of prematurity in middle-income countries. Lancet 1997;9070:1214

9 Gerinec A, Chynoransky M, Smykova T. Causes of blindness and low vision of children in the Slovak Republic. Cs Oftalmol 1990;2:121-7.

10 Doci J, Juhas T, Klisenbauer D, et al. Occurrence of blindness in Slovak Socialistic Republic. Cs Oftalmol 1988;4: 241-6.

11 Gilbert CE, Canovas R, Hagan M, et al. Causes of childhood blindness: results from West Africa, South India and Chile. Eye 1993;7:184-8.

12 Goggin M, O'Keefe M. Childhood blindness in the Republic of Ireland: a national survey. $\mathrm{Br} \quad \mathcal{F}$ Ophthalmol 1991;75:425-9.

13 Rosenberg T, Flage T, Hansen E, et al. Visual impairment in Nordic Children. II. Aetiological factors. Acta Ophthalmol (Copenh) 1992;70:155-64.

14 Rosenberg $\mathrm{T}$, Flage $\mathrm{T}$, Hansen $\mathrm{E}$, et al. Incidence of registered visual impairment in the Nordic child population. Br f Ophthalmol 1996;80:49-53.

15 Phillips CI, Levy AM, Newton M, et al. Blindness in school children: importance of heredity, congenital cataract, and prematurity. Br f Ophthalmol 1987;71:578-84.

16 Gilbert C, Rahi J, Eckstein M, et al. Hereditary disease as a cause of childhood blindness: regional variation. Ophthalmol Genet 1995;16:1-10. 